\title{
Effects of rivastigmine hydrogen tartrate and donepezil hydrochloride on the cognitive function and mental behavior of patients with Alzheimer's disease
}

\author{
XIAOHONG ZHANG ${ }^{1}$, RONGHUA YU ${ }^{1}$, HUILIN WANG ${ }^{2}$ and RUIFENG ZHENG ${ }^{1}$ \\ Departments of ${ }^{1}$ Rehabilitation and ${ }^{2}$ Neurology, Luoyang Central Hospital, Luoyang, Henan 471000, P.R. China
}

Received July 23, 2019; Accepted April 6, 2020

DOI: $10.3892 /$ etm.2020.8872

\begin{abstract}
The present study aimed to examine the effects of rivastigmine hydrogen tartrate and donepezil hydrochloride on the cognitive function and mental behavior of patients with Alzheimer's disease (AD). For this purpose, a total of 126 patients with AD admitted to Luoyang Central Hospital from January, 2018 to December, 2018 were enrolled. Patients were divided into different groups according to the treatment they selected. Patients treated with single-agent donepezil were separated into a monotherapy group $(n=56)$, and patients receiving donepezil plus rivastigmine were placed in the combination group $(n=70)$. Before and after treatment, the cognitive functions, mental behavior and quality of life of the patients in the two groups were respectively evaluated by the Alzheimer's Disease Assessment Scale-Cognitive Subscale (ADAS-Cog), the Mini-Mental State Examination (MMSE), the Blessed-Roth Dementia Scale (BRDS) and the QOL-AD. In addition, the serum bradykinin level was detected by enzyme-linked immunosorbent assay. Following treatment, the MMSE score, BRDS, ADAS-Cog and QOL-AD scores were improved compared with those before treatment $(\mathrm{P}<0.05)$. However, following treatment, the 4 scores in the combination group were significantly higher than those in the monotherapy group $(\mathrm{P}<0.05)$. No significant differences were observed in the incidence of adverse reactions between the 2 groups $(\mathrm{P}>0.05)$. Following treatment, the bradykinin level in both groups was significantly decreased $(\mathrm{P}<0.05)$, although the decrease in the combination group was more significant than that in the monotherapy group $(\mathrm{P}<0.05)$. On the whole, the findings of the present study indicate that rivastigmine hydrogen tartrate used in combination with donepezil hydrochloride relieves the symptoms and improves the quality of life of patients with AD
\end{abstract}

Correspondence to: Dr Ruifeng Zheng, Department of Rehabilitation, Luoyang Central Hospital, 288 Zhongzhou Middle Road, Luoyang, Henan 471000, P.R. China

E-mail: rbf9ix@163.com

Key words: rivastigmine hydrogen tartrate, donepezil hydrochloride, Alzheimer's disease, bradykinin, cognitive function more effectively, which may be related to the reduction of the bradykinin level in these patients.

\section{Introduction}

Alzheimer's disease (AD) is the currently most common neurodegenerative disease. According to the official statistics in $2015,110,561$ individuals succumbed to the disease, rendering $\mathrm{AD}$ the 6th most common cause of mortality in the United States and the 5th cause of mortality for Americans aged $\geq 65$ years. The number of patients with AD in the United States are expected to increase to 13.8 million by the middle of the century $(1,2)$. Patients with AD have a number of neurofibrillary tangles and amyloid plaques in their brains. Plaques, astrocyte proliferation, neuronal dystrophy, neuronal loss and vascular variations are signs of the disease. AD results in the loss of mental, behavioral and cognitive functions and learning ability, which causes great distress to patients and nursing staff (3). Patients with AD are mainly treated with acetylcholinesterase inhibitors, which enhance cholinergic neurotransmission in the brain by reducing the degradation rate of acetylcholine in the synaptic cleft (4). Donepezil and rivastigmine are commonly used acetylcholinesterase inhibitors that can improve the treatment of patients with AD (5-8). There are a number of studies available on the separate application of these two drugs. For example, it has been reported that rivastigmine significantly improves cognitive function and daily living ability in patients with AD compared with those administered the placebo (9). In addition, previous research has indicated that compared with the placebo, donepezil significantly improves the overall function of patients with $\mathrm{AD}$, and is safer and well-tolerated (10). At present, however, to the best of our knowledge, there is no evidence available on the effects of the combination of rivastigmine and donepezil in the treatment of $\mathrm{AD}$.

The kallikrein-kinin system (KKS) is considered as an important pathophysiological mediator of cerebrovascular dysfunction, neuroinflammation and amyloid $\beta$-protein (A $\beta$ ) pathology in AD (11). Bradykinin released by KKS is a pro-inflammatory mediator with a series of physiological actions in the periphery (12). In a previous study, the chronic administration of bradykinin B1 and B2 receptor antagonists was shown to improve amyloidosis-related cerebral hypoperfusion and vascular reactivity, thereby relieving the symptoms 
of patients with AD (13). Another study demonstrated that bradykinin increased the intracellular calcium concentration $\left[\left(\mathrm{Ca}^{2+}\right) \mathrm{i}\right]$ in astrocytes, while donepezil reduced this increase. Donepezil inhibited bradykinin-induced inflammatory responses through the nicotinic acetylcholine receptor (nAChR) and PI3K/Akt pathways in astrocytes, so as to treat AD (14). Therefore, rivastigmine hydrogen tartrate and donepezil hydrochloride may suppress the symptoms of AD by inhibiting the bradykinin level.

In the present study, changes in the cognitive functions and mental behavior of patients with AD were observed through rivastigmine hydrogen tartrate and donepezil hydrochloride, so as to compare their efficacy on AD and to compare the effects between the two drugs. In addition, the effects of the drugs on serum bradykinin levels in the patients were examined.

\section{Patients and methods}

Inclusion and exclusion criteria. The present study was a non-randomized controlled trial. A total of 126 patients with AD admitted to Luoyang Central Hospital from January, 2018 to December, 2018 were enrolled. Patients treated with the single-agent donepezil were included in the monotherapy group $(n=56)$, and patients receiving donepezil plus rivastigmine were in the combination group $(n=70)$. Patients were divided into different groups according to the treatment they selected.

The inclusion criteria were as follows: Patients who met the diagnostic criteria for AD (15); patients $<80$ years of age, but $>50$ years of age; patients who had a primary school education or higher, and were able to complete the treatments and follow-up tests; patients who did not receive antipsychotic drugs or cholinesterase inhibitors 4 weeks prior to enrollment; patients with a Minimum Mental State Examination (MMSE) score (16) between 12-27 points. The exclusion criteria were as follows: Patients with allergy or contraindications to donepezil and rivastigmine; patients with mental illnesses other than AD; patients with poor treatment compliance; patients with heart, liver and kidney insufficiency; patients who had suffered severe head injuries. In the present study, patients and their families were informed and signed an informed consent form. The study was approved by the Medical Ethics Committee of Luoyang Central Hospital.

Grouping and treatment methods. According to the severity of the patients' symptoms, patients in the monotherapy group were administered $1-2$ tablets $(5 \mathrm{mg} / 1$ tablet) of donepezil hydrochloride tablets (purchased from Chongqing Zein Pharmaceutical Co., Ltd.), once/day. On the basis of the monotherapy group, patients in the combination group were administered rivastigmine hydrogen tartrate capsules (purchased from Novartis) $1.5 \mathrm{mg} /$ time and twice/day. The dosage could be changed to $6 \mathrm{mg} /$ time and once/day according to the patients' tolerance. Patients in both groups were treated for 6 months.

Scoring standards. Before and after treatment, the MMSE (14) was used to score the patients' memory, attention, language competence and other cognitive functions in the monotherapy and combination groups. A total of $27-30$ points indicated normal cognitive functions, whereas $<27$ points indicated cognitive impairment. The lower the score was, the more severe the cognitive impairment was.

Before and after treatment, the Blessed-Roth Dementia Scale (BRDS) (17) was used to evaluate the patients' ability of social/daily living, cognition of common sense and character changes in the monotherapy and combination groups. A score of $\leq 7$ points indicated no dementia, whereas a score of $>7$ points indicated dementia. The higher the score was, the more severe the dementia was.

Before and after treatment, the Alzheimer's Disease Assessment Scale-Cognitive Subscale (ADAS-Cog) (18) was used to score the patients' memory, language competence, ability to use, inferential capability, orientation and other abilities in the monotherapy and combination groups. The scoring system was between 0-70 points. The higher the score was, the more severe the injury was.

Before and after treatment, the AD quality of life scale (QOL-AD) (19) was used to evaluate the quality of life of patients in the 2 groups, including physical condition, energy, mood, memory and other 13 items, with a total score of 52 . The higher the score, the greater the quality of life.

Detection of serum bradykinin level before and after treatment. Before and after treatment, $5 \mathrm{ml}$ of fasting venous blood was extracted in the morning from patients in the 2 groups, placed in centrifuge tubes and centrifuged $\left(1,500 \times \mathrm{g}, 4^{\circ} \mathrm{C}\right.$, $10 \mathrm{~min}$ ) for multiple times to obtain the supernatant, namely serum. The serum was stored in a refrigerator at $-80^{\circ} \mathrm{C}$ for later use. Before and after treatment, the serum bradykinin level was determined by enzyme-linked immunosorbent assay (ELISA). An ELISA kit was purchased from Abcam. Standard wells, sample wells to be tested and blank control wells were set up on an ELISA plate. The standard well was supplemented with $50 \mu \mathrm{l}$ of standard substances with various concentrations, while the sample well to be tested was added with $40 \mu \mathrm{l}$ of sample diluent and then $10 \mu \mathrm{l}$ of the samples to be tested. The plate was sealed with a microplate sealer and incubated at $37^{\circ} \mathrm{C}$ for $1 \mathrm{~h}$. After the sealer was removed and the liquid in the wells was discarded, the plate was washed with washing liquid over 5 min 3 times and dried with absorbent paper towels. Subsequently, the standard well and the sample well to be tested were added with $50 \mu \mathrm{l}$ of enzyme-labeled reagents. The plate was sealed with a microplate sealer and incubated at $37^{\circ} \mathrm{C}$ for $1 \mathrm{~h}$. After the sealer was removed and the liquid in the wells was discarded, the plate was washed with washing liquid over 5 min 3 times and dried with absorbent paper towels. Subsequently, each well was supplemented with $50 \mu \mathrm{l}$ of substrates $\mathrm{H}_{2} \mathrm{O}_{2}$ and TMB in turn, and then developed at $37^{\circ} \mathrm{C}$ for $10-15 \mathrm{~min}$ in the dark after the substrates were mixed evenly. Finally, each well was supplemented with $50 \mu 1$ of stop solution to cease the reaction. The optical density values of each well were detected at $450 \mathrm{~nm}$ using a multifunctional microplate reader (CLARIOstar, BMG LABTECH).

Statistical analysis. SPSS 18.0 (IBM Corp.) was used for statistical analysis. In the present study, count data, such as place of residence and the number of adverse reactions 
Table I. Comparison of general information [n(\%)].

\begin{tabular}{|c|c|c|c|c|}
\hline Groups & Monotherapy group $(\mathrm{n}=56)$ & Combination group $(\mathrm{n}=70)$ & $\chi^{2}$ & P-value \\
\hline Age & & & 0.202 & 0.653 \\
\hline$<65$ years old & $23(41.07)$ & $26(37.14)$ & & \\
\hline$\geq 65$ years old & $33(58.93)$ & $44(62.86)$ & & \\
\hline Exercise & & & 0.015 & 0.902 \\
\hline Yes & $21(37.50)$ & $27(38.57)$ & & \\
\hline No & $35(62.50)$ & $43(61.43)$ & & \\
\hline Place of residence & & & 0.161 & 0.689 \\
\hline City & $30(53.57)$ & $40(57.14)$ & & \\
\hline Countryside & $26(46.43)$ & $30(42.86)$ & & \\
\hline Nationality & & & 0.358 & 0.550 \\
\hline Han & $50(89.29)$ & $60(85.71)$ & & \\
\hline National minorities & $6(10.71)$ & $10(15.29)$ & & \\
\hline Educational level & & & 0.129 & 0.720 \\
\hline$<$ Senior high school & $40(71.43)$ & $52(74.29)$ & & \\
\hline$\geq$ Senior high school & $16(28.57)$ & $18(25.71)$ & & \\
\hline Body weight & & & 0.082 & 0.775 \\
\hline$<55 \mathrm{KG}$ & $21(37.50)$ & $28(40.00)$ & & \\
\hline$\geq 55 \mathrm{KG}$ & $35(62.50)$ & $42(60.00)$ & & \\
\hline Marital status & & & 1.994 & 0.369 \\
\hline Married & $47(83.93)$ & $52(74.29)$ & & \\
\hline Unmarried & $6(10.71)$ & $10(14.29)$ & & \\
\hline Widowed & $3(5.36)$ & $8(11.42)$ & & \\
\hline Food preference & & & 0.113 & 0.737 \\
\hline Bland & $36(64.29)$ & $47(67.14)$ & & \\
\hline Spicy & $20(35.71)$ & $23(32.86)$ & & \\
\hline
\end{tabular}

were expressed in terms of number/percentage [n (\%)]. The comparisons between technical data were performed using the Chi-squared test or Fisher's exact test. ADAS-Cog MMSE scores were expressed as the means \pm standard deviation (SD). One-way ANOVA followed by Tukey's HSD test was used for comparison of measurement data, expressed by $F$ values. $\mathrm{P}<0.05$ was considered to indicate a statistically significant difference.

\section{Results}

Comparison of general information. No significant differences were observed between the combination and monotherapy groups as regards age, exercise habits, place of residence, nationality, educational level, body weight, marital status and food preference $(\mathrm{P}>0.05)$. Further details are presented in Table I.

Comparison of MMSE score before and after treatment. Patients in both groups cooperated to complete the treatment. Following treatment, the MMSE score in the monotherapy group increased from $16.12 \pm 1.74$ to $22.23 \pm 1.99(\mathrm{P}<0.05)$, and the score in the combination group increased from $15.85 \pm 2.19$ to $26.23 \pm 2.17(\mathrm{P}<0.05)$. Following treatment, the MMSE score in the combination group was significantly higher than that in the monotherapy group $(\mathrm{P}<0.05)$. Further details are presented in Table II.

Comparison of the BRDS score before and after treatment. Following treatment, the BRDS score in the monotherapy group decreased from $14.78 \pm 1.67$ to $9.23 \pm 1.28(\mathrm{P}<0.05)$, and the score in the combination group decreased from $14.33 \pm 1.81$ to $7.18 \pm 0.95(\mathrm{P}<0.05)$. Following treatment, the BRDS score in the combination group was significantly lower than that in the monotherapy group $(\mathrm{P}<0.05)$. Further details are presented in Table III.

Comparison of the ADAS-Cog score before and after treatment. Following treatment, the ADAS-Cog score in the monotherapy group decreased from $29.67 \pm 3.03$ to $22.24 \pm 3.98$ $(\mathrm{P}<0.05)$, and the score in the combination group decreased from $30.15 \pm 2.89$ to $18.24 \pm 3.67(\mathrm{P}<0.05)$. Following treatment, the ADAS-Cog score in the combination group was significantly lower than that in the monotherapy group $(\mathrm{P}<0.05)$. Further details are presented in Table IV.

Comparison of the QOL-AD score before and after treatment. Following treatment, the QOL-AD score in the monotherapy group decreased from $26.24 \pm 5.89$ to $35.24 \pm 5.78(\mathrm{P}<0.05)$, and the score in the combination group decreased from $25.28 \pm 6.45$ 
Table II. Comparison of MMSE score before and after treatment (means $\pm \mathrm{SD})$.

\begin{tabular}{lcc}
\hline Groups & $\begin{array}{c}\text { Monotherapy } \\
\text { group }(\mathrm{n}=56)\end{array}$ & $\begin{array}{c}\text { Combination } \\
\text { group }(\mathrm{n}=70)\end{array}$ \\
\hline Before treatment & $16.12 \pm 1.74$ & $15.85 \pm 2.19$ \\
After treatment & $22.23 \pm 1.99^{\mathrm{a}}$ & $26.23 \pm 2.17^{\mathrm{a}, \mathrm{b}}$ \\
F value & 16.894 & 27.783 \\
P-value & $<0.001$ & $<0.001$ \\
\hline
\end{tabular}

${ }^{\mathrm{a}} \mathrm{P}<0.05$, compared with the same group before treatment; ${ }^{\mathrm{b}} \mathrm{P}<0.05$, compared with the monotherapy group after treatment.

Table III. Comparison of BRDS score before and after treatment (means $\pm \mathrm{SD})$.

\begin{tabular}{lcc}
\hline Groups & $\begin{array}{c}\text { Monotherapy } \\
\text { group }(\mathrm{n}=56)\end{array}$ & $\begin{array}{c}\text { Combination } \\
\text { group }(\mathrm{n}=70)\end{array}$ \\
\hline Before treatment & $14.78 \pm 1.67$ & $14.33 \pm 1.81$ \\
After treatment & $9.23 \pm 1.28^{\mathrm{a}}$ & $7.18 \pm 0.95^{\mathrm{a}, \mathrm{b}}$ \\
F value & 18.768 & 28.398 \\
P-value & $<0.001$ & $<0.001$ \\
\hline
\end{tabular}

${ }^{\mathrm{a}} \mathrm{P}<0.05$, compared with the same group before treatment; ${ }^{\mathrm{b}} \mathrm{P}<0.05$, compared with the monotherapy group after treatment.

Table IV. Comparison of ADAS-Cog score before and after treatment (means $\pm \mathrm{SD})$.

\begin{tabular}{lcc}
\hline Groups & $\begin{array}{c}\text { Monotherapy } \\
\text { group }(\mathrm{n}=56)\end{array}$ & $\begin{array}{c}\text { Combination } \\
\text { group }(\mathrm{n}=70)\end{array}$ \\
\hline Before treatment & $29.67 \pm 3.03$ & $30.15 \pm 2.89$ \\
After treatment & $22.24 \pm 3.98^{\mathrm{a}}$ & $18.24 \pm 3.67^{\mathrm{a}, \mathrm{b}}$ \\
F value & 10.752 & 19.278 \\
P-value & $<0.001$ & $<0.001$ \\
\hline
\end{tabular}

${ }^{\mathrm{a}} \mathrm{P}<0.05$, compared with the same group before treatment; ${ }^{\mathrm{b}} \mathrm{P}<0.05$, compared with the monotherapy group after treatment.

to $43.24 \pm 5.35(\mathrm{P}<0.05)$. Following treatment, the QOL-AD score in the combination group was significantly higher than that in the monotherapy group $(\mathrm{P}<0.05)$. Further details are presented in Table V.

Comparison of adverse reactions. No allergic reactions occurred during the treatment period in the 2 groups, and adverse reactions were treated with symptomatic treatment. No significant differences were observed in the main adverse reactions in appetite loss, headache, vomiting, muscle spasm, insomnia, sleepiness and diarrhea between the 2 groups, and there were no significant differences in the total number of affected patients (with at least 1 adverse event) between
Table V. Comparison of QOL-AD score before and after treatment (means $\pm \mathrm{SD})$.

\begin{tabular}{lcc}
\hline Groups & $\begin{array}{c}\text { Monotherapy } \\
\text { group }(\mathrm{n}=56)\end{array}$ & $\begin{array}{c}\text { Combination } \\
\text { group }(\mathrm{n}=70)\end{array}$ \\
\hline Before treatment & $26.24 \pm 5.89$ & $25.28 \pm 6.45$ \\
After treatment & $35.24 \pm 5.78^{\mathrm{a}}$ & $43.24 \pm 5.35^{\mathrm{a}, \mathrm{b}}$ \\
F value & 8.852 & 16.759 \\
P-value & $<0.001$ & $<0.001$ \\
\hline
\end{tabular}

${ }^{\mathrm{a}} \mathrm{P}<0.05$, compared with the same group before treatment; ${ }^{\mathrm{b}} \mathrm{P}<0.05$, compared with the monotherapy group after treatment.

the two groups $(\mathrm{P}>0.05)$. Further details are presented in Table VI.

Comparison of bradykinin level. Following treatment, the bradykinin level in the monotherapy group was $16.48 \pm 2.99 \mu \mathrm{g} / \mathrm{l}$, significantly lower than $22.13 \pm 2.18 \mu \mathrm{g} / \mathrm{l}$ before treatment $(\mathrm{P}<0.05)$. Following treatment, the level in the combination group was $11.37 \pm 2.51 \mu \mathrm{g} / 1$, significantly lower than $22.55 \pm 2.49 \mu \mathrm{g} / 1$ before treatment $(\mathrm{P}<0.05)$. Following treatment, the bradykinin level in the combination group was significantly lower than that in the monotherapy group $(\mathrm{P}<0.05)$. Further details are presented in Table VII and Fig. 1.

\section{Discussion}

There are currently 47 million patients with AD worldwide. The morbidity rate of the disease increases with the aging of the population, which brings great mental and economic burdens to families. It is estimated that 74.7 million individuals will suffer from dementia by the year 2030, and the nursing expenses for these patients will increase to about 2 trillion US dollars $(20,21)$. At present, there is no cure available for $\mathrm{AD}$, although the symptoms can be relieved by drug interventions (4). Therefore, it is of great significance for patients with $\mathrm{AD}$ and their families to identify therapeutic regimens with which to attenuate the deterioration of AD symptoms.

Patients with AD exhibit significant choline deficiency (22). Therefore, cholinesterase inhibitors are mainly used to reduce the metabolic rate of acetylcholine and suppress its hydrolysis, thus increasing acetylcholine in the body and improving the choline deficiency, and relieving AD symptoms (23). As a selective and reversible cholinesterase inhibitor widely used in clinical practice, donepezil hydrochloride inhibits the hydrolysis of acetylcholine and increases its concentration in the human body, thereby improving information transfer in the brain $(24,25)$. As a dual cholinesterase inhibitor, rivastigmine hydrogen tartrate inhibits cholinesterase activity and reduces the loss of presynaptic cholinergic function, thus reducing the degradation of acetylcholine in synaptic cleft and increasing cholinergic signal transduction, and then improving cognition and memory $(26,27)$. There are number of previous studies available confirming the efficacy of rivastigmine hydrogen 
Table VI. Comparison of adverse reactions [cases (\%)].

\begin{tabular}{lcccc}
\hline Groups & Monotherapy group, $\mathrm{n}=56[\mathrm{n}(\%)]$ & Combination group, $\mathrm{n}=70[\mathrm{n}(\%)]$ & $\chi^{2}$ & P-value \\
\hline Decreased food appetite & $3(5.36)$ & $5(7.14)$ & 0.167 & 0.683 \\
Headache & $2(3.57)$ & $4(5.71)$ & 0.315 & 0.575 \\
Vomiting & $4(7.14)$ & $7(10.00)$ & 0.319 & 0.572 \\
Muscle spasms & $2(3.57)$ & $5(7.14)$ & 0.756 & 0.385 \\
Insomnia & $3(5.36)$ & $6(8.57)$ & 0.485 & 0.486 \\
Drowsiness and fatigue & $5(8.93)$ & $4(5.13)$ & 0.120 & 0.729 \\
Diarrhea & $2(3.57)$ & $6(8.57)$ & 1.308 & 0.253 \\
Total number of affected patients & $21(37.50)$ & $37(52.86)$ & 2.954 & 0.086
\end{tabular}

Table VII. Comparison of bradykinin level ( $\mu \mathrm{g} / 1$, means $\pm \mathrm{SD})$.

\begin{tabular}{lcc}
\hline Groups & $\begin{array}{c}\text { Monotherapy } \\
\text { group }(\mathrm{n}=56)\end{array}$ & $\begin{array}{c}\text { Combination } \\
\text { group }(\mathrm{n}=70)\end{array}$ \\
\hline Before treatment & $22.13 \pm 2.18$ & $22.55 \pm 2.49$ \\
After treatment & $16.48 \pm 2.99^{\mathrm{a}}$ & $11.37 \pm 2.51^{\mathrm{a}, \mathrm{b}}$ \\
F value & 11.273 & 25.573 \\
P-value & $<0.001$ & $<0.001$ \\
\hline
\end{tabular}

${ }^{\mathrm{a}} \mathrm{P}<0.05$, compared with the same group before treatment; ${ }^{\mathrm{b}} \mathrm{P}<0.05$, compared with the monotherapy group after treatment.

tartrate and donepezil hydrochloride in the treatment of AD, however, their combined use in the treatment of the disease has been rarely studied (28-30). The results of the present study demonstrated that the MMSE, BRDS, ADAS-Cog, and QOL-AD scores of the 2 groups were significantly improved following treatment, and the improvement of the combination group was more significant. No significant differences were found between the 2 groups in the occurrence of adverse reactions. These findings suggest that compared with donepezil hydrochloride alone, rivastigmine hydrogen tartrate combined with donepezil hydrochloride can relieve the symptoms and improve the quality of life of patients with AD more effectively, and the adverse reactions are not increased.

Recently, it has been indicated that bradykinin released by KKS plays an important role in the central nervous system (31). Brain inflammation aggravates the pathology of $\mathrm{AD}$, and bradykinin $\mathrm{B} 1$ receptors play a regulatory role in brain inflammation and in amyloid deposition of AD in mice. Therefore, bradykinin $\mathrm{B} 1$ receptors may involve microglia/macrophages, thus affecting the progression of AD (32). Bradykinin B2 receptor antagonists provide significant protection for synaptic loss and cognitive impairment induced by $A \beta 1-40$ in mice, by reducing the activation of microglia and pro-inflammatory protein levels, as well as inhibiting MAPK signaling pathway and the activation of transcription factors (33). According to the study by Ashby et al, the bradykinin level was significantly higher in patients with AD, and it may affect cerebral blood flow and vascular permeability (34). This indicates that the reduction

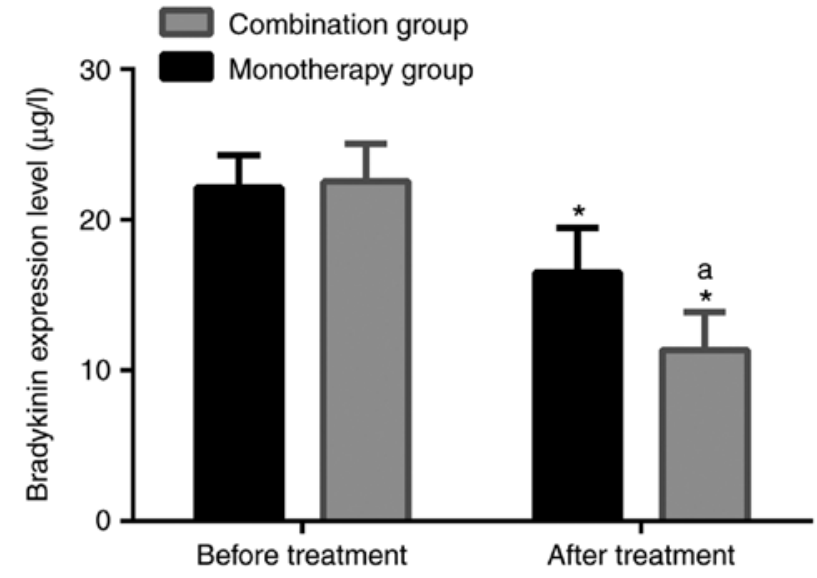

Figure 1. Comparison of bradykinin level. The results of ELISA revealed that following treatment, the levels of bradykinin in the serum of the 2 groups were significantly reduced, and the serum level of bradykinin was significantly lower in the combination group than that in the monotherapy group $(\mathrm{P}<0.05)$. $\mathrm{P}<0.05$, compared with before treatment in the same group; ${ }^{a} \mathrm{P}<0.05$, compared with the monotherapy group after treatment.

of the bradykinin level can relieve the symptoms of patients with $\mathrm{AD}$. In the present study, following treatment, the bradykinin level in the 2 groups significantly decreased and the AD symptoms were relieved, which was consistent with the results of the above-mentioned studies. The decrease in the combination group was stronger compared with that in the monotherapy group, suggesting that the two drugs may relieve AD symptoms by reducing bradykinin level.

In conclusion, compared to treatment with donepezil hydrochloride alone, rivastigmine hydrogen tartrate combined with donepezil hydrochloride can relieve the symptoms and improve the quality of life of patients with AD more effectively, which may be related to the reduction of the bradykinin level. However, in the present study, the efficacy was not compared between the 2 drugs and other drugs. Additionally, the mechanisms of action between rivastigmine hydrogen tartrate, donepezil hydrochloride and bradykinin were not explored. Therefore, the conclusions presented herein are limited. In the future, large-scale randomized controlled trials or prospective cohort studies need to be conducted, and individual differences and potential interference factors will be controlled, in order to further confirm the reliability of the conclusions of the present study. 


\section{Acknowledgements}

Not applicable.

\section{Funding}

No funding was received.

\section{Availability of data and materials}

The datasets used and/or analyzed during the present study are available from the corresponding author on reasonable request.

\section{Authors' contributions}

XZ conceived the study and wrote the manuscript. RY analyzed and interpreted the patient general data. HW performed ELISA. RZ was responsible for observation indicators analysis. All authors read and approved the final manuscript.

\section{Ethics approval and consent to participate}

The study was approved by the Ethics Committee of Luoyang Central Hospital. Patients who participated in this research, signed the informed consent and had complete clinical data. Signed written informed consents were obtained from the patients and/or guardians.

\section{Patient consent for publication}

Not applicable.

\section{Competing interests}

The authors declare that they have no competing interests.

\section{References}

1. Anand R, Gill KD and Mahdi AA: Therapeutics of Alzheimer's disease: Past, present and future. Neuropharmacology 76: 27-50, 2014.

2. Alzheimer's Association: 2018 Alzheimer's disease facts and figures. Alzheimer Dement 14: 367-429, 2018.

3. Lombardo S and Maskos U: Role of the nicotinic acetylcholine receptor in Alzheimer's disease pathology and treatment. Neuropharmacology 96: 255-262, 2015.

4. Birks JS, Chong LY and Grimley Evans J: Rivastigmine for Alzheimer's disease. Cochrane Database Syst Rev 9: CD001191, 2015 (Epub ahead of print)

5. Islam MM, Gurung AB, Bhattacharjee A, Aguan K and Mitra S: Human serum albumin reduces the potency of acetylcholinesterase inhibitor based drugs for Alzheimer's disease. Chem Biol Interact 249: 1-9, 2016.

6. Tsoi KK, Chan JY, Leung NW, Hirai HW, Wong SY and Kwok TC: Combination therapy showed limited superiority over monotherapy for Alzheimer disease: A meta-analysis of 14 randomized trials. J Am Med Dir Assoc 17: 863.e1-e8, 2016.

7. D'onofrio G, Sancarlo D, Addante F, Ciccone F, Cascavilla L, Paris F, Elia AC, Nuzzaci C, Picoco M, Greco A, et al: A pilot randomized controlled trial evaluating an integrated treatment of rivastigmine transdermal patch and cognitive stimulation in patients with Alzheimer's disease. Int J Geriatr Psychiatry 30: 965-975, 2015

8. Han HJ, Kwon JC, Kim JE, Kim SG, Park JM, Park KW, Park KC, Park KH, Moon SY, Seo SW, et al: Effect of rivastigmine or memantine add-on therapy is affected by butyrylcholinesterase genotype in patients with probable Alzheimer's disease. Eur Neurol 73: 23-28, 2015
9. Birks JS and Grimley Evans J: Rivastigmine for Alzheimer's disease. Cochrane Database Syst Rev 2015: CD001191, 2015.

10. Maher-Edwards G, Dixon R, Hunter J, Gold M, Hopton G, Jacobs G, Hunter J and Williams P: SB-742457 and donepezil in Alzheimer disease: A randomized, placebo-controlled study. Int J Geriatr Psychiatry 26: 536-544, 2011.

11. Nokkari A, Abou-El-Hassan H, Mechref Y, Mondello S, Kindy MS, Jaffa AA and Kobeissy F: Implication of the Kallikrein-Kinin system in neurological disorders: Quest for potential biomarkers and mechanisms. Prog Neurobiol 165-167: 26-50, 2018.

12. Zhao WQ and Alkon DL: Alzheimer's disease diagnosis based on mitogen-activated protein kinase phosphorylation. U.S. Pat Appl 9: 188-595, 2015.

13. Ni R, Kindler DR, Waag R, Rouault M, Ravikumar P, Nitsch R, Rudin M, Camici GG, Liberale L, Kulic L and Klohs J: fMRI reveals mitigation of cerebrovascular dysfunction by bradykinin receptors 1 and 2 inhibitor noscapine in a mouse model of cerebral amyloidosis. Front Aging Neurosci 11: 27, 2019.

14. Makitani K, Nakagawa S, Izumi Y, Akaike A and Kume T: Inhibitory effect of donepezil on bradykinin-induced increase in the intracellular calcium concentration in cultured cortical astrocytes. J Pharmacol Sci 134: 37-44, 2017.

15. McKhann GM, Knopman DS, Chertkow H, Hyman BT, Jack CR Jr, Kawas CH, Klunk WE, Koroshetz WJ, Manly JJ, Mayeux R, et al: The diagnosis of dementia due to Alzheimer's disease: Recommendations from the National Institute on Aging-Alzheimer's Association workgroups on diagnostic guidelines for Alzheimer's disease. Alzheimers Dement 7: 263-269, 2011.

16. Arevalo-Rodriguez I, Smailagic N, Roqué I Figuls M, Ciapponi A, Sanchez-Perez E, Giannakou A, Pedraza OL, Bonfill Cosp X and Cullum S: Mini-mental state examination (MMSE) for the detection of Alzheimer's disease and other dementias in people with mild cognitive impairment (MCI). Cochrane Database Syst Rev 2015: CD010783, 2015.

17. Blessed G, Tomlinson BE and Roth M: Blessed-Roth dementia scale (DS). Psychopharmacol Bull 24: 705-708, 1988.

18. Podhorna J, Krahnke T, Shear M and Harrison JE; Alzheimer's Disease Neuroimaging Initiative: Alzheimer's disease assessment scale-cognitive subscale variants in mild cognitive impairment and mild Alzheimer's disease: Change over time and the effect of enrichment strategies. Alzheimers Res Ther 8: 8, 2016.

19. Logsdon RG, Gibbons LE, McCurry SM and Teri L: Quality of life in Alzheimer's disease: Patient and caregiver reports. J Ment health Aging 5: 21-32, 1999.

20. Winblad B, Amouyel P, Andrieu S, Ballard C, Brayne C, Brodaty H, Cedazo-Minguez A, Dubois B, Edvardsson D, Feldman H, et al: Defeating Alzheimer's disease and other dementias: A priority for European science and society. Lancet Neurol 15: 455-532, 2016

21. Cummings J, Aisen PS, DuBois B, Frölich L, Jack CR Jr, Jones RW, Morris JC, Raskin J, Dowsett SA and Scheltens P: Drug development in Alzheimer's disease: The path to 2025. Alzheimers Res Ther 8: 39, 2016.

22. Shao ZQ: Comparison of the efficacy of four cholinesterase inhibitors in combination with memantine for the treatment of Alzheimer's disease. Int J Clin Exp Med 8: 2944-2948, 2015.

23. Godyń J, Jończyk J, Panek D and Malawska B: Therapeutic strategies for Alzheimer's disease in clinical trials. Pharmacol Rep 68: 127-138, 2016.

24. Chase TN, Farlow MR and Clarence-Smith K: Donepezil plus Solifenacin (CPC-201) treatment for Alzheimer's disease. Neurotherapeutics 14: 405-416, 2017.

25. Kearney MC, Caffarel-Salvador E, Fallows SJ, McCarthy HO and Donnelly RF: Microneedle-mediated delivery of donepezil: Potential for improved treatment options in Alzheimer's disease. Eur J Pharm Biopharm 103: 43-50, 2016.

26. Mohamed LA, Keller JN and Kaddoumi A: Role of P-glycoprotein in mediating rivastigmine effect on amyloid- $\beta$ brain load and related pathology in Alzheimer's disease mouse model. Biochim Biophys Acta 1862: 778-787, 2016.

27. Oh YS, Kim JS and Lee PH: Effect of rivastigmine on behavioral and psychiatric symptoms of Parkinson's disease dementia. J Mov Disord 8: 98-102, 2015.

28. Cummings J, Lai TJ, Hemrungrojn S, Mohandas E, Yun Kim S, Nair G and Dash A: Role of donepezil in the management of neuropsychiatric symptoms in Alzheimer's disease and dementia with Lewy bodies. CNS Neurosci Ther 22: 159-166, 2016. 
29. Nieto RA, Deardorff WJ and Grossberg GT: Efficacy of rivastigmine tartrate, transdermal system, in Alzheimer's disease. Expert Opin Pharmacother 17: 861-870, 2016.

30. Montero-Odasso M, Muir-Hunter SW, Oteng-Amoako A, Gopaul K, Islam A, Borrie M, Wells J and Speechley M Donepezil improves gait performance in older adults with mild Alzheimer's disease: A phase II clinical trial. J Alzheimers Dis 43: 193-199, 2015.

31. Bitencourt RM, Guerra de Souza AC, Bicca MA, Pamplona FA, de Mello N, Passos GF, Medeiros R, Takahashi RN, Calixto JB and Prediger RD: Blockade of hippocampal bradykinin B1 receptors improves spatial learning and memory deficits in middle-aged rats. Behav Brain Res 316: 74-81, 2017.
32. Asraf K, Torika N, Danon A and Fleisher-Berkovich S: Involvement of the bradykinin $B_{1}$ receptor in microglial activation: In vitro and in vivo studies. Front Endocrinol (Lausanne) 8: 82, 2017.

33. Bicca MA, Costa R, Loch-Neckel G, Figueiredo CP, Medeiros R and Calixto $\mathrm{JB}: \mathrm{B}_{2}$ receptor blockage prevents $\mathrm{A} \beta$-induced cognitive impairment by neuroinflammation inhibition. Behav Brain Res 278: 482-491, 2015.

34. Ashby EL, Love S and Kehoe PG: Assessment of activation of the plasma kallikrein-kinin system in frontal and temporal cortex in Alzheimer's disease and vascular dementia. Neurobiol Aging 33: 1345-1355, 2012. 